\section{CHOLERA IN HAITI'S ARTIBONITE VALLEY}

The Artibonite River and its tributaries flow through two of Haiti's administrative departments, the Central and Artibonite Departments. On 21 October 2010, the national laboratory of the Haitian Ministry of Health (MSPP) confirmed reports from communities near the mouth of the Artibonite River that 44 cases of patients with fever, vomiting, and explosive diarrhea were, indeed, cholera (1). In grim testimony to the potential of this illness to kill, there were also reports of people found dead by the roadside. Within 24 hours of these first case reports, the nearest regional public hospital, Hôpital Saint Nicolas, in the city of Saint Marc, was overwhelmed, with more than 500 cases reported and more than 100 deaths. At the same time, the city of Mirebalais, near the headwaters of the Artibonite River, also reported cases. Within a week, the epidemic had spread to 4 of Haiti's 10 departments, with two departments reporting $99.4 \%$ of the cases [Artibonite (76.5\%) and Central (22.9\%)]. At that time, 4722 hospitalizations and 303 deaths were reported (2). One month later, MSPP reported a total of 77208 hospital visits, 34248 hospitalizations, and 1751 deaths. The overall case mortality rate, including deaths outside the hospital is $2.3 \%$, while the inhospital case fatality rate for the country is $3.6 \%$ (3). However, because of the isolation of most communities in these departments, difficulty in access to care, and paucity of providers, actual numbers of victims and deaths are assuredly higher.

Several environmental features help explain why cholera surfaced in the Artibonite Valley and spread so rapidly to other departments. The Artibonite River, particularly near its mouth, is crisscrossed with irrigation canals and ditches that service rice paddies and sugarcane fields. People bathe in and drink from the river as well as the canals and ditches. Modern sanitation is virtually absent from the Artibonite and the Central Plateau (this is true for almost all of rural Haiti). The epidemic surfaced at the end of the rainy season, when high water tables combined with storm runoff to flood makeshift latrines.

Once established, the national road system facilitated the spread of the epidemic. These roads are heavily trafficked, with peasants bringing agricultural products to market and people traveling between the countryside and major cities.

The last reports of cholera in Haiti were in 1962 and the last reported cases on the island of Hispaniola were in 1972. Thus, it is unlikely that this outbreak originated in Haiti. Shortly after the outbreak, many Haitians questioned whether the MINUSTAH
(French acronym for the United Nations mission in Haiti, Mission des Nations Unies pour la Stabilisation en Haiti) base just outside Mirebalais might be the source. The base is staffed by Nepalese troops, and cholera is endemic in Nepal. The Associated Press reported that the latrines from the MINUSTAH camp drained raw sewage into a tributary of the Artibonite River and the U.S. Centers for Disease Control and Prevention confirmed that the strain (Vibrio cholerae 0 -139) causing the outbreak originated in "South Asia." More recently, in December 2010, the Associated Press reported that French epidemiologist Dr. Renaud Piarroux confirmed the origin of the epidemic was most likely the MINUSTAH camp (4). This was subsequently confirmed by the Centers for Disease Control and Prevention (5).

As soon as cholera was confirmed, several nongovernmental organizations active in the central plateau and Artibonite Department joined forces with MSPP's regional representatives to mount a response to the epidemic. The following nongovernmental organizations participated in creating the cholera treatment center in Mirebalais: American Red Cross, Concern Worldwide, Cuban Collaboration, Digicel Foundation, Jewish Distribution Committee, J/P Haitian Relief Organization, Médecins Sans Frontières (Belgium), Partners in Health, Progress \& Development Through the Youth of Haiti, Project Medishare, and World Vision. This report includes data provided by Project Medishare, a nongovernmental organization affiliated with the University of Miami Miller School of Medicine.

Project Medishare has a long history of engagement and collaboration in the central plateau as well as making available startup funding and in-kind contributions as a result of its efforts after the earthquake. Over the past decade, it has cultivated a Haitian workforce centered on community health workers who serve as peer educators and providers. These factors contributed to its ability to mount a rapid and effective response. In addition, its stateside academic partner, the University of Miami Miller School of Medicine, was able to provide invaluable technical assistance with regard to effective strategies for prevention and treatment.

The leadership of all the participating organizations met with the regional MSPP representatives the day after cholera was confirmed. They drafted a strategic plan to respond to the epidemic. A cohort of community health workers from Project Medishare and Partners in Health was deployed from the central plateau to Artibonite Department, while nurses and doctors (some Haitian, some Cuban, and some Ameri- 
can volunteers) complemented existing staff at Saint Marc and Mirebalais.

Oral rehydration therapy packets, intravenous solutions, cots, buckets, bleach, and soap were donated and distributed to cholera treatment centers in Saint Marc, Mirebalais, and Hinche. At the same time, bullhorns, oral rehydration packets, bleach, and soap were donated to Project Medishare and distributed to community health workers to facilitate classes on cholera prevention and early treatment at a community level throughout the two departments.

A tent that served as part of Project Medishare's field hospital in the months after the earthquake was taken out of storage and set up as a cholera treatment center in Mirebalais. The Mirebalais facility opened on 7 November 2010 in partnership with Partners in Health. To date, community health workers have provided community-based classes to 21500 individuals and distributed 18000 oral rehydration therapy packets and 180000 bottles and tablets of bleach to 1800 families.

The issue of the source and rapid spread of cholera is important for three reasons:

1. Having been stigmatized as vectors of the AIDS epidemic, Haitians do not want to be blamed as the cause of cholera.

2. There has been simmering resentment in Haiti of the United Nations mission. Many Haitians want, at the very least, the United Nations to be held accountable for better sanitation in their own camps, and, at best, to have more public works projects. Even if the United Nations camp is not the source of cholera, it should not dump untreated waste into rivers that are a source of drinking water.

3. The cholera epidemic highlights the need for long overdue clean water and sanitation projects throughout the country.

A recent report praises the often maligned MSPP for its prompt and effective response (6). In addition, it now appears that the epidemic is beginning to abate in the Central and Artibonite Departments (7). We postulate that the collaborative programs for prevention and treatment brought forward by MSPP, Project Medishare, Partners in Health, and other nongovernmental organizations contributed to this abatement of the epidemic and can serve as a community-based pre- vention and treatment model as the country mounts a national response. Our experience also suggests that an extremely low mortality rate in cholera treatment centers can be achieved with oral rehydration therapy and limited use of antibiotics.

Marie Chery

University of Miami School of Nursing Miami, Florida, United States of America

Michel Dodard

University of Miami Miller School of Medicine Global Institute for Community Health and Development Miami, Florida, United States of America

Arthur Fournier

University of Miami Miller School of Medicine Global Institute for Community Health and Development Miami, Florida, United States of America

\section{REFERENCES}

1. Pan American Health Organization. Emergency Operations Center Situation Report 1. PAHO responds to cholera outbreak in Haiti. Washington, D.C.: PAHO; 21 October 2010. Available from: http://new.paho.org/hq/index.php?option=com content\&task $=$ view\&id $=4367 \&$ Itemid $=1926$ Accessed 30 November 2010.

2. Pan American Health Organization. Emergency Operations Center Situation Report 6. Cholera outbreak in Haiti. Washington, D.C.: PAHO; 27 October 2010. Available from: http://new.paho.org/disasters/index.php?option=com docman\&task=doc_view\&gid=1271. Accessed 30 November 2010.

3. United Nations Office for the Coordination of Humanitarian Affairs, Haiti. Cholera Situation Report 22. Port-au-Prince, Haiti: OCHA; 30 November 2010. http://www.reliefweb. int/sites/reliefweb.int/files/resources/35A524477C180F 9F492577EC000DAF91-Full_Report.pdf Accessed 30 November 2010.

4. Haiti cholera likely from UN troops, expert says. Associated Press. 7 December 2010.

5. Piarroux R, Barrais R, Faucher B, Haus R, Piarroux M, Gaudart J, et al. Understanding the cholera epidemic, Haiti. Emerg Infect Dis. 2011;17(7):1161-8.

6. Dowell SF, Tappero JW, Frieden TR. Public health in Haitichallenges and progress. N Engl J Med. 2011;364:300-1.

7. Pan American Health Organization. Epidemiological alert: weekly update on the cholera situation EW 52 (December 26 2010 to January 1st 2011). Washington, D.C.: PAHO; 11 January 2011. 